\title{
Lung Hilum Carcinoma
}

National Cancer Institute

\section{Source}

National Cancer Institute. Lung Hilum Carcinoma. NCI Thesaurus. Code C7454.

A lung carcinoma arising from the hilum of the lung. 